\title{
Diagnosing barriers to make strategic decisions in manufacturing business units
}

\author{
Mohammadali Shah Housseini ${ }^{\mathrm{a}}$ and Sina Asgari ${ }^{\mathrm{b}}$
}

${ }^{a}$ Department of Management, University of Tehran, Tehran, Iran ${ }^{b}$ Department of Management, University of Tehran, Kish Campus, Iran C H R O N I C L E A B S T R C T

Article history:

Received October 28, 2015

Received in revised format

November 28, 2015

Accepted February 10, 2016

Available online

February 11, 2016

Keywords:

Strategic decision

Strategy

Implementation

Pakshoo Company

\begin{abstract}
Nowadays, due to the transition from the old economic model to the global village constituting patterns, different functional requirements are needed. In other words, for success in the modern production management, strategic decisions must create the conditions for taking new systems for enterprises and create conditions for the competitiveness of manufacturing firms. This paper presents a survey on diagnosing barriers to make strategic decisions in a manufacturing firm named Pakshoo company in city of Tehran, Iran. The study tries to find the obstacles for the implementation of strategic decisions in this firm. The study determines 14 different factors influencing on the development of strategic planning and using analytical hierarchy process, prioritize them, accordingly. In our survey, behavioral factors are considered as the most important factors followed by structural and context issues.
\end{abstract}

\section{Introduction}

The new competitive atmosphere has obliged the managers and directors of different organizations to take a closer look at the outer world and appreciate their vital rules and beyond that look for a way to develop and propagate their organizations (Ansoff \& McDonnell, 1990; Bryson, 2011). According to Toffler (1990), change is a process, which dominates and has cast a shadow on all of our lives. Therefore, it is of great significance to study it more closely (Parkinson et al., 1984). The intensivelychanging conditions of the atmosphere and the ever-increasing competitions among small and large companies in the present business environment of the world force the directors to take new managing decisions each day. These decisions occasionally violate the previous decisions in a way that implementation of new decisions requires fundamental changes in an organization (Pearce, 2000). These changes can embrace a wide range within an organization: re-structuring, culture-building, a new operational plan, and exploiting new manpower are among them. But proportionate to the changes, 
which occur at the strategic level of directors' decisions, organizations are generally unable to accommodate themselves in an opposite manner. Therefore, there are lots of problems in executing these strategic decisions. In fact, there are some questions which are among the key barriers to the successful implementation of these decisions and are common among several organizations, of course, with a minor changes among which we can refer to examples such as conflicting priorities and a weak vertical communications, lack of support from director and the managing director in implementing the strategy of the organization and the motiveless and improper human resource (Brenes et al., 2008). It is evident that making a decision will be followed by implementing and assessing it and lack of directing sufficient effort toward each one of these steps can deactivate and neutralize decent decisions (David, 1986).

\section{Theoretical foundations}

Managing the navigation of the science and art of implementation and assessment of the respected decisions are of the fundamental functions of the organizations in a way that these series of operations could lead to meeting the organizations' objectives (Floyd \& Carney, 1992). Strategic management is a process by which managers set the long-term directions of the activities of a company, set specific operational goals, and design the strategies for achieving the goals by noting the internal and external conditions for designing and choose and exercise practical plans for implementing the strategies (Hamidizadeh, 2007, 2008).

The fundamental features of strategic management can be enumerated in summary as follows:

1. They have a broad-based viewpoint in the course of time. (i.e. mid-range and short-term goals result from long-term plans.) 2. They have a belief in the necessity of the existence of a long-term and common prospect in an organization until a constructive and goal-oriented movement occurs. 3 . It is mission-oriented and its key goal is to perform the organization's mission. 4. Be a believer in the necessity of existence of coherent and integrated decisions in the whole sections of the company. 5. It essentially has a military essence and origin and is seriously applicable to defense affairs. 6. Its key function is based on the continuous assessment of the status quo (i.e. internal and external organizational environment) and finding some solutions to move toward an optimal condition. 7. It is basically dependent on the personal and organizational creativity and intelligence. 8 . It presents a decent framework for assessing the situation and movement of the company (i.e. productivity and function.) 9. They mostly have a broad-based view and rarely enters into minute details of any affair. 10. Finding a chance or opportunity discovery and threat identification incessantly is among the main practical features of them (Rahman Seresht, 2005).

Strategic management involves three general categories (functions): 1. Strategic decision-making based on the strategic analysis by the strategist to realize the situation of an organization. 2. Formularize the practical and plausible ways, determine and choose the best strategy and way. 3. Implementing the selected strategies and assessing them (Danesh Ashtiani, 2005). Kazemi (2011) investigated and scrutinized the influential factors in implementing the strategies in the public sector. The results indicated that viewing the various steps in the cycle of formulating a strategy as inseparable, compatibility of the potentialities of an organization with its strategies, power of the human resource of the company, organizational structure, inter-organizational processes, and the environmental factors are among the factors influencing the implementation of strategies in the public sector. In other study researcher investigated the relations between the influential factors or variables in implementing the strategies in the public sector. The results indicated that the operations by the administrative organs, appropriateness of structure, human resource, internal and processes and a proper distribution of financial resources were influential in the implementation of strategies. Rahman Seresht (2005), in a study investigated the process of implementing a strategy. The results indicated that implementation of 
strategies involves turning strategic plans into practice through integrating and uniting the whole organization for the implementation of a strategy and harmonize the methods of running the operations of an organization with the requirements of a successful performance.

Fard et al. (2011), in a study investigated the implementation and execution of strategic management in an organization. The results indicated that organizational culture could be a starting point for an active movement of an organization and/or an obstacle to its progress. Without observing the organizational culture the strategic management needs, which are peculiar to the period of fast changes in the internal and external environment of an organization cannot be successful. Fatehi (1996), in a study, investigated the impact of organizational culture on the implementation of organizational strategies. The results indicated that an improper organizational culture could turn into one of the organizational barriers to implement a strategy. This problem arises as the culture of an organization is ready for making use of an old strategy but does not extend welcome to the new strategy. Farajpour and Noorossana (2011) investigated the reasons for the failure of strategies in an organization. The results indicated that for the reasons of failure of strategies we can refer to the incorrect transfer of a strategy throughout the whole organization and also limitation of budget and time and the inefficiency of resources while implementing projects which occasionally would not bear a strategic priority and a high significance for achieving the goals but they appropriate the bulk of improvement resources.

\section{The proposed study}

Any conceptual model is considered as a starting point and a cornerstone for doing studies and researches in a way that it determines the intended variables of the research and their interrelations. In other words, it can be said that, ideally, the conceptual model and the analytical instrument for a strategy is to start and to perform a research in a way that it is expected to investigate and test the variables, the relations and interactions among them while conducting a research and if deemed necessary do some modifications in them and add some factors to them or remove some factors from them (Strauss \& Corbin, 1990).

\subsection{Conceptual Model of the research}

In this survey, we present a method to determine and prioritize the barriers to make strategic decisions. Fig. 1 shows some of the factors influence on making strategic decisions.

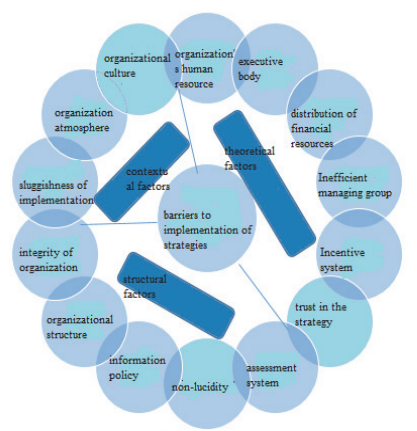

Fig. 1. Conceptual Model of the research

In the present research we are considering the Analytical Hierarchical Process (AHP) Method (Saaty, 1988) for the data to prioritize the identified barriers in the research literature. Since the pairwise comparisons should be performed by the experts in this domain and also by considering the point that the number of strategic managers in our case study, Pakshoo Company, is limited and amounts to fifteen, the questionnaires were distributed among the whole statistical universe. In this research, after collecting the fifteen distributed questionnaires among managers of the company we turned to merge the questionnaires in order to perform a group decision-making by making use of geometrical mean. 


\subsubsection{Ranking structural factors}

Fig. 2 shows the results of pairwise comparisons and AHP implementation for the structural barriers for applying the strategic decisions using the software choice Expert concerning the prioritization of structural obstacles to the implementation and execution of strategic decisions. The quantity of compatibility index of the model equals 0.09 which is less than or equal to 0.1 and it is indicative of the acceptable compatibility of the system.

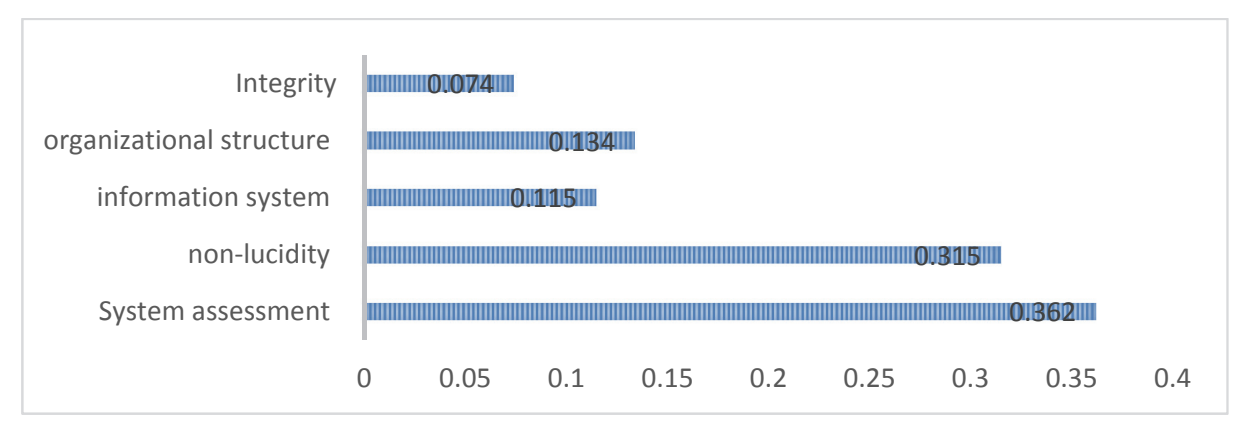

Fig. 2. The results of the implementation of AHP method for ranking barriers

Based on the performed prioritization in the section of structural factors the inexistence of an evaluation system for the strategies of the organization is presented as the key barrier to actualization of strategic decisions. After that obscurity in strategic decisions, organizational structures, inexistence of an information system and at last the organizational disintegrate are the oncoming priorities.

\subsubsection{Prioritization of behavioral factors}

Fig. 3 presents the output of Expert choice software concerning the prioritization of the structural barriers for the implementation and the execution of strategic decisions. The rate of compatibility coefficient of the model equals 0.09 which is less than or equal to 0.1 and is indicative of the acceptable compatibility of the system.

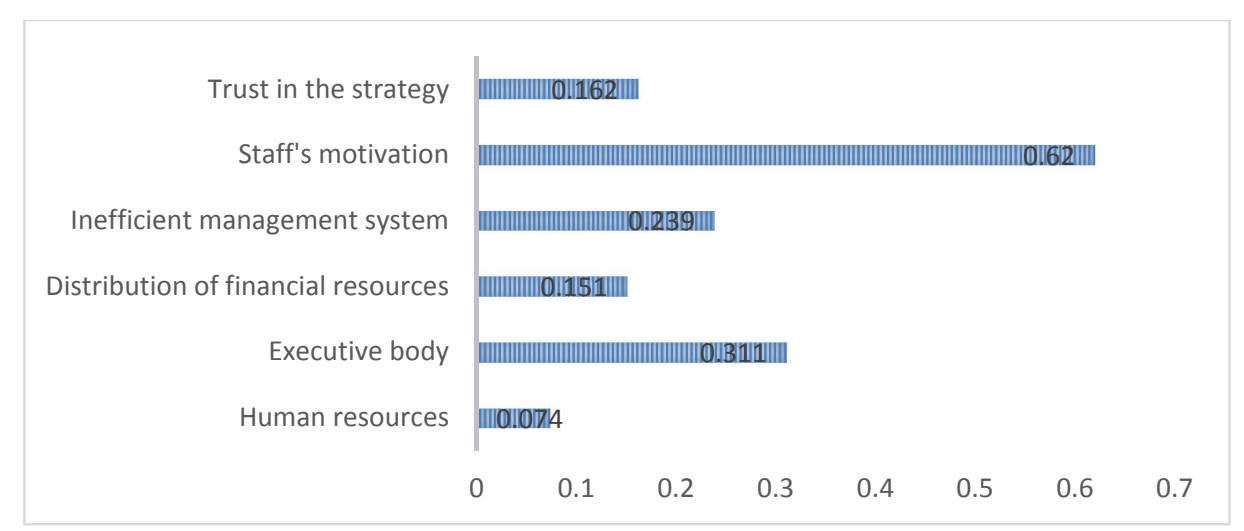

Fig. 3. The results of the implementation of AHP method for ranking behavioral factors

\subsubsection{Prioritizing in terms of the biggest barriers}

Next, Fig. 4 presents the results of the ranking sluggishness of implementation, organizational culture and organizational environment as the main issues to blame for development appropriate strategies. As we can observe from the results of Fig. 4, organizational culture is the most important factor followed by organizational environment and sluggishness of implementation. The quantity of the consistency ratio is 0.0083 which is less than 0.1 and it is indicative of the acceptable compatibility of the system. 


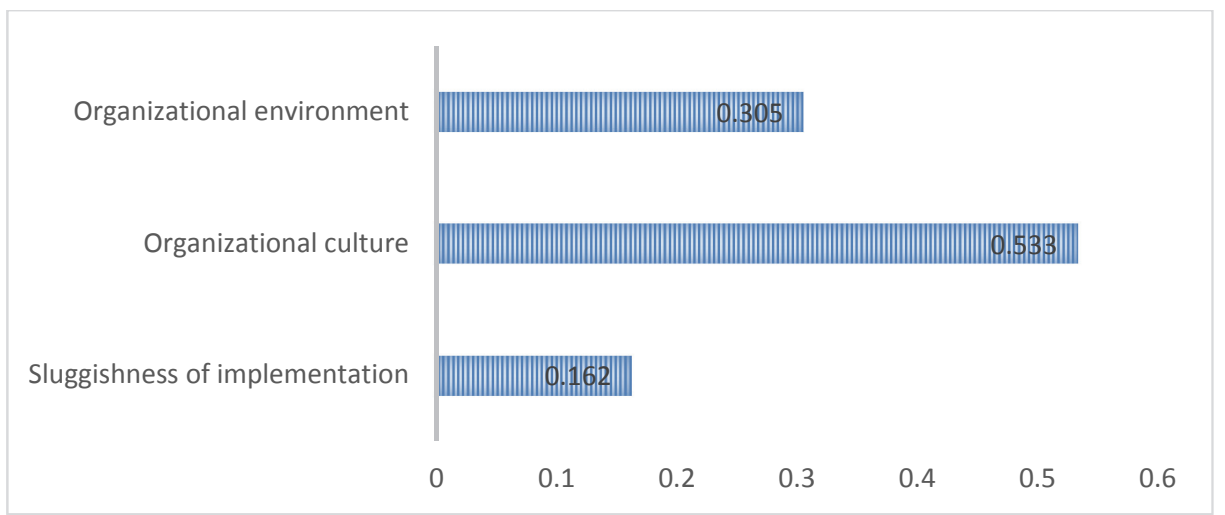

Fig. 4. The results of the implementation of AHP method for ranking main factors

\subsubsection{Ranking factors in terms of execution of strategic decisions}

Finally, Fig. 5 shows the ranking for factors influencing on execution of strategic decisions.

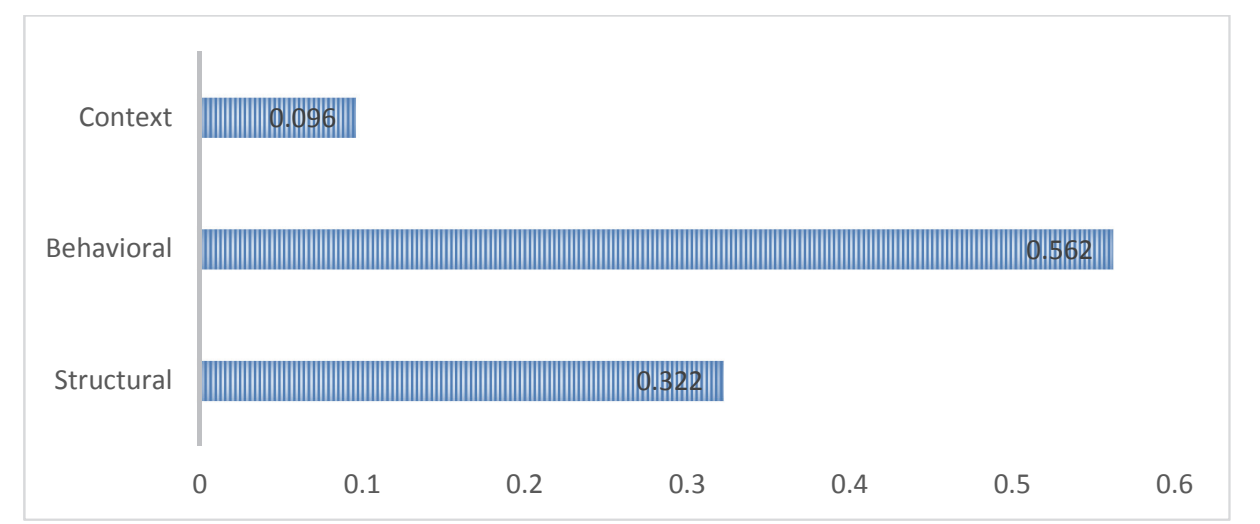

Fig. 5. The results of the implementation of AHP method for ranking strategic decisions

Again consistency ratio is within desirable level (0.000838), which means the comparison of these factors were meaningful. In our survey, Behavioral factors are considered as the most important factors followed by structural and context.

\section{Result and recommendations}

In the current highly-competitive production and business environment, mangers have to be able to make strategic decisions about their organizational' needs and execute them in their firms. Unsuccessful implementation of managerial decisions is a subject which harshly threatens the effectuality and the efficiency of strategic decisions. It is urgent that managers could obtain an appropriate understanding of the influential factors of their success or failure since awareness of the key variables which are pertinent to the results of strategic decisions helps them bring out better results for the organization as a result of a better management. Being aware of these factors it is evident that the predictability of managers' decisions would augment and the possibility of measurement among various choices while making decision will become ripe for it. As mentioned before, in this study at first we turned to identify the barriers to implement and execute strategic decisions in the manufacturing organizations. For this purpose, theoretical studies and the literature review were investigated. In order to systematize the process of the study the three-dimensional organizational structure was used and the identified barriers were studied in the form of this structure. Based on this, fourteen key barriers were out of literature review in the area of implementation and the execution of strategic decisions were identified that in the behavioral branch five barriers, in the behavioral branch six barriers, and in the 
contextual branch three barriers were identified. Being aware of these factors and also categorization of them by considering the essence of barriers in various areas, we have determined the sections which should bear the responsibility of fulfilling these functions for better management of organizations. To sum up, in the performed pairwise comparison behavioral factors were viewed as the key barriers for the implementation of strategic decisions followed by the structural and contextual branches as the next priorities.

\section{References}

Ansoff, H. I., \& McDonnell, E. J. (1990). Implanting Strategic Management(Vol. 2). New York: Prentice Hall.

Brenes, J. C., Rodríguez, O., \& Fornaguera, J. (2008). Differential effect of environment enrichment and social isolation on depressive-like behavior, spontaneous activity and serotonin and norepinephrine concentration in prefrontal cortex and ventral striatum. Pharmacology Biochemistry and Behavior, 89(1), 85-93.

Bryson, J. M. (2011). Strategic planning for public and nonprofit organizations: A guide to strengthening and sustaining organizational achievement (Vol. 1). John Wiley \& Sons.

Danesh Ashtiani, M. B. (2005). Comprehensive defensive-security system of strategic management. Quarterly Periodical of Defensive and Strategic Studies. Supreme National Defense University, 21, 49.

David, F. R. (1986). Fundamentals of strategic management (Vol. 1). Macmillan Pub Co.

Farajpour, G., \& Noorossana, R. (2011). An integrated framework for formulate and implement strategies at the Islamic Republic of Iran postal company. International Journal of Industrial Engineering and Production Management, 22(1), 77-90.

Fard, H. D., Moshabbaki, A., Abbasi, T., \& Hassanpoor, A. (2011). Strategic management in the public sector: reflections on it's applicability to Iranian public organizations. Public Organization Review, 11(4), 385-406.

Fatehi, K. (1996). International management: A cross-cultural and functional perspective. Prentice Hall.

Floyd, R. A., \& Carney, J. M. (1992). Free radical damage to protein and DNA: mechanisms involved and relevant observations on brain undergoing oxidative stress. Annals of Neurology, 32(S1), S22S27.

Hamidizadeh, M. R. (2007). Smart and Creative Decision-Making: Emotional Intelligence. Tehran. Termeh Publication.

Hamidizadeh, M. R. (2008). Modern Decision-making. Tehran. Supreme National Defense University.

Kazemi, D., Behan, J., \& Boniauto, M. (2011). Improving teaching strategies in an undergraduate community health nursing $(\mathrm{CHN})$ program: Implementation of a service-learning preceptor program. Nurse education today, 31(6), 547-552.

Parkinson, C. N., Rustomji, M. K., \& Sapre, S. A. (1984). Great ideas in management. IBH Publishers.

Pearce, J. A., Robinson, R. B., \& Subramanian, R. (2000). Strategic management: Formulation, implementation, and control. Columbus, OH: Irwin/McGraw-Hill.

Rahman Seresht, H. (2005). Management Strategies. Tehran. Ide-pardazan-e-fan-o-honar Company Publication.

Saaty, T. L. (1988). What is the analytic hierarchy process? (pp. 109-121). Springer Berlin Heidelberg. Strauss, A., \& Corbin, J. (1990). Basics of qualitative research (Vol. 15). Newbury Park, CA: Sage. Toffler, A. (1990). Future shock. Bantam.

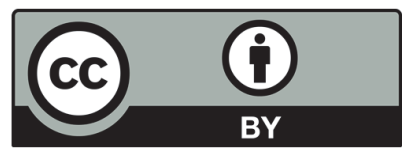

(C) 2016 by the authors; licensee Growing Science, Canada. This article is an open access article distributed under the terms and conditions of the Creative Commons Attribution (CC-BY) license (http://creativecommons.org/licenses/by/4.0/). 